\title{
OPERACIONALIZAÇÃO DE UMA GROUNDED THEORY: O PERCURSO METOdOLÓGICO
}

\author{
GROUNDED THEORY OPERATIONALIZATION: \\ THE METHODOLOGICAL ROUTE
}

\author{
Paulo Cristiano de Oliveira ${ }^{1}$ \\ Marina Keiko Nakayama ${ }^{2}$
}

\begin{abstract}
Resumo: Pesquisadores encontram dificuldades para desenvolver estudos utilizando o método da Grounded Theory (GT). Este artigo traz o percurso metodológico da operacionalização de uma GT. A investigação que proporcionou este relato buscou esclarecer quais são e como atuam os fatores que influenciam a utilização do Learning Management System na gestão da Educação a Distância, em uma universidade, a partir da experiência dos seus gestores. A pesquisa adotou a corrente Straussiana: o problema foi explicitamente definido e foram desenvolvidas a codificação aberta, a axial e a seletiva, com dados coletados a partir de entrevistas semiestruturadas e documentos. A principal contribuição deste artigo é apresentar os procedimentos operacionais para a construção de uma GT.
\end{abstract}

Palavras-chave: Grounded theory; Método; Pesquisa qualitativa; Procedimentos operacionais.

\begin{abstract}
Researchers has been found difficult to develop studies using the Grounded Theory (GT) method. This article presents the methodological route about an operationalization of a GT. The research that provided this description sought to clarify what are and how they act the factors that influence the use of the Learning Management System in the management of Distance Education in a university, based on the experience of its managers. The research adopted the Straussian current: the problem was explicitly defined and open, axial and selective coding were developed, with data collected from documents and semistructured interviews. The main contribution of this article is to present the operational procedures for the construction of a GT.
\end{abstract}

Keywords: Grounded Theory; Method; Qualitative Research; Operational procedures.

\section{Introdução}

Pesquisadores têm encontrado inúmeras dificuldades para operacionalizar estudos utilizando o método da Grounded Theory (APRAMIAN et al., 2016; MURPHY, KLOTZ e KREINER, 2016). Bianchi e Ikeda (2008) colocam que a evolução da Grounded Theory (GT) acabou por gerar uma lista de riscos e situações de exceção. Para as autoras, os

\footnotetext{
${ }^{1}$ Doutor em Engenharia e Gestão do Conhecimento pela Universidade Federal de Santa Catarina (UFSC). Professor do Ensino Superior no Centro Estadual de Educação Tecnológica Paula Souza (CEETEPS), São Paulo, São Paulo, Brasil. E-mail: oliveirapco@ hotmail.com

${ }^{2}$ Doutora em Administração pela Universidade Federal do Rio Grande do Sul (UFRGS). Professora titular do Departamento de Engenharia do Conhecimento da Universidade Federal de Santa Catarina (UFSC), Florianopólis, Santa Catarina, Brasil. E-mail: marina@egc.ufsc.br
} 
desafios do método concentram-se na difícil sua operacionalização, desde a definição inicial dos elementos de estudo até a formulação da teoria e no papel e postura do pesquisador (SCHRÖEDER, 2009), sendo que esse papel merece destaque na análise do método de pesquisa GT. Para Hopfer e Maciel-Lima (2008), o método é frequentemente mal compreendido, pois é difícil criar definições para explicar uma interação social. Neste sentido, a GT exige um trabalho de campo intensivo e longo, sendo considerado denso e de difícil compreensão, onde as fronteiras da pesquisa são de definição complexa.

Paradigmas são realizações científicas que, por um momento, são universalmente reconhecidas. Os paradigmas fornecem modelos de problemas e soluções para uma comunidade de cientistas (KUHN, 1970). Na área de Sistemas de Informação (SI), a utilização do paradigma interpretativista, em que se considera a subjetividade do pesquisador (MORGAN, 1980) e, em especial, a abordagem qualitativa (TAYLOR; BOGDAN, 1998; CRESWELL, 2014; DENZIN; LINCOLN, 2005), não tem se apresentado como principal forma para a condução das pesquisas. Como exemplo disso pode-se citar a revisão de literatura de Shaikh e Karjaluoto (2015), que analisou mais de 150 artigos, publicados de janeiro de 2000 a dezembro de 2014 e identificou inúmeras lacunas nas pesquisas em SI. Esses mesmos autores sugerem que há escassez de estudos qualitativos na área e recomendam a realização de pesquisas com essa abordagem, incluindo estudos sobre LMS e impactos da pós-adoção ou uso contínuo de SI, onde o estudo relatado por este texto se insere.

Considerando a relevância da discussão proposta (SHAIKH; KARJALUOTO, 2015), o ineditismo de pesquisas que utilizem GT na área de SI (BANDEIRA-DEMELLO; CUNHA, 2003; PINTO; SANTOS, 2012), bem como as dificuldades para a operacionalização enfrentadas pelos pesquisadores qualitativos (BIANCHI; IKEDA, 2008; HOPFER; MACIEL-LIMA, 2008; SCHRÖEDER, 2009; SUDDABY, 2006), o presente artigo pode ser entendido como uma reflexão original sobre a operacionalização de uma Grounded Theory (GT) na área de Sistemas de Informação.

Dessa forma, o objetivo deste artigo é apresentar o percurso metodológico da operacionalização de uma GT. O estudo no qual o percurso foi desenvolvido buscou esclarecer quais são e como atuam os fatores que influenciam a utilização do Learning Management System (LMS) na gestão da Educação a Distância (EaD) em uma universidade pública brasileira, a partir da experiência dos seus gestores.

A seguir são apresentados os fundamentos teóricos de GT, o desenho da pesquisa relatada por este artigo, os participantes, o processo explorado e os instrumentos de coleta 
de dados. Na sequência são relatadas a operacionalização do pré-campo, do campo e do pós-campo de pesquisa. Ao final, são apresentadas as considerações finais e as lições aprendidas.

\section{Fundamentos teóricos}

Barley Glaser e Anselm Strauss publicaram The Discovery of Grounded Theory, em 1967, onde havia a primeira definição e formulação do então, novo método para a pesquisa qualitativa. Na introdução, o texto continha uma definição breve da abordagem, dizendo que a "Grounded Theory consistia em um método geral de análise comparativa [...] e um conjunto de procedimentos capazes de gerar [sistematicamente] uma teoria fundada em dados" (TAROZZI, 2011, p. 17, grifo do autor). Grounded Theory, para seus fundadores, é um "método geral" e contemporaneamente é um "conjunto de procedimentos". Entende-se que compreende um discurso racional global, uma análise teórica e uma orientação sobre o método. Daquela primeira definição, houve uma sucessão de percepções e opiniões sobre como deve ser entendida uma GT e sobre sua classificação entre os métodos e metodologias (APRAMIAN et al., 2016). Para Glaser e outros, é essencialmente uma metodologia. Para Corbin (STRAUSS; CORBIN, 2008) é um método. Para Charmaz (2009) é uma constelação de métodos. Para Tarozzi (2011) pode ser entendida como uma metodologia que contém várias indicações de procedimentos, as quais assumem diversas declinações, segundo a escola e os autores utilizados. De uma maneira geral, a GT pode ser considerada tanto um olhar teórico sobre o reconhecimento e a análise de dados, ou seja, um método geral, e também um conjunto de procedimentos e instrumentos para recolher e analisá-los. Para os pesquisadores que utilizam a abordagem é fundamental saber que existem esses dois níveis e estar consciente do nível de abstração em que estes se colocam.

Uma pesquisa conduzida sob a ótica da GT logra êxito se gerar uma teoria, ou seja, uma interpretação racional, articulada, sistemática e densa capaz de dar conta de uma realidade. A GT busca produzir uma teoria complexa e articulada, sublinhando com força a ligação íntima entre pesquisa teórica e pesquisa empírica e se colocando no espaço que une teoria e realidade (TAROZZI, 2011). Segundo o mesmo autor, a teoria produzida com a abordagem da GT tem uma forte e sólida base empírica, pois é extraída a partir dos dados. Considerado como o principal quadro teórico de referência da GT, o interacionismo simbólico pressupõe que os seres humanos são seres simbólicos, que 
produzem sua própria cultura e interpretam a história através de arcabouços representativos (BLUMER, 1969). A análise social e psicossocial se dá nos modos que os sujeitos trazem significado ao mundo em que vivem. Mas a atribuição de significado ao mundo não é um processo individual, pois acontece pela interação entre indivíduos. Assim o interacionismo simbólico busca os elementos invariáveis, as formas de vida social que estão por trás das redes de significado, dos processos de mudança, das interações entre sujeitos.

O estudo na qual essa reflexão se baseia utilizou Strauss e Corbin (2008) como autores-chave para sua condução. Esta escolha se justifica porque na investigação se partiu de uma questão que identificou claramente o problema estudado e foram desenvolvidas a codificação aberta, a axial e a seletiva para a análise sistemática de dados, privilegiado a coleta de dados a partir de entrevistas semiestruturadas e documentos, conforme orientação dos autores da abordagem full conceptual description. Além disso, a abordagem Straussiana já foi utilizada, ao menos parcialmente, em outros estudos desenvolvidos no grupo de pesquisa, que o precederam.

Bandeira-de-Mello e Cunha (2003) ao abordar o rigor e a fundamentação empírica da GT, dizem que se pode questionar se o método produz, realmente, uma "boa ciência", mas que essas fragilidades podem ser superadas a partir da leitura dos cânones da ciência interpretadas, por eles, a partir de Strauss e Corbin (2008). A validade interna do método é comprovada visto que a realidade é socialmente construída através da percepção dos indivíduos, quando o pesquisador deve identificar a realidade observada a partir dos dados coletados. A confiabilidade ou replicabilidade é o grau de consistência entre os achados do estudo e os dados coletados, reconhecendo que é impossível recriar experimentos controlados nos contextos organizacionais e que o comportamento humano não é regido por leis universais que geram sempre os mesmos resultados. Com relação à validade externa ou generalização, dizem que o método tem como proposta especificar as condições em que ocorrem determinados eventos e suas consequências. Portanto, quanto maior as variações incorporadas nos dados, mais diferentes são as condições contempladas e mais geral será a teoria substantiva. Concordando-se com Suddaby (2006), entende-se que os desafios na condução de uma GT podem atenuados quando os pesquisadores adquirem experiência e descobrem maneiras eficientes para analisar a informação disponível. Para isso é fundamental assumir a importância de documentar todo o processo de pesquisa, incluindo-se a formalização das decisões tomadas no decorrer do estudo, sendo que os memorandos ocupam importância central. Neste sentido, 
destaca-se que este artigo é fruto dessa formalização, indicada pelos autores, que versam sobre o rigor em GT.

\section{Desenho da pesquisa}

O desenho da pesquisa compreendeu o conjunto de procedimentos e técnicas para sua operacionalização. Ele foi baseado em três fundamentos: Tarozzi (2011) indicou as fases para o processo de pesquisa da GT. A visão de Strauss e Corbin (2008) serviu como o fio condutor para o desenvolvimento da teoria substantiva, enquanto processo analítico. Bandeira-de-Mello e Cunha (2003) orientaram os procedimentos operacionais. Essas três visões se integraram, para que o estudo pudesse ser executado.

As dez fases do desenho da pesquisa foram:

- Fase 1 - Identificação da área de investigação: uma área de pesquisa foi identificada, considerando-se sua complexidade e globalidade (STRAUSS; CORBIN, 2008).

- Fase 2 - Definição de uma pergunta gerativa da pesquisa: no início, a pergunta de pesquisa foi uma "pergunta gerativa, aberta, não excessivamente focalizada" (STRAUSS; CORBIN, 2008), mas que no decorrer do estudo ganhou forma.

- Fase 3 - Definição dos instrumentos: os instrumentos principais foram entrevista semiestruturada e a análise de documentos. Nesta fase foram escolhidos os primeiros sujeitos e também foi definido o acesso ao campo (STRAUSS; CORBIN, 2008).

- Fase 4 - Codificação aberta: processo analítico por meio do qual os conceitos foram identificados e suas propriedades e dimensões foram descobertas (STRAUSS; CORBIN, 2008). Ajudou a definir os temas que seriam tratados nas próximas entrevistas.

- Fase 5 - Elaboração de memorandos: se apresentaram em várias fases do processo de construção da GT (STRAUSS; CORBIN, 2008). Foram registradas observações dos pesquisadores com relação à condução das entrevistas e as reflexões que conduziram às escolhas de amostragem teórica.

- Fase 6 - Amostragem teórica: se tornou mais objetiva e focada na medida em que a pesquisa progredia, sendo que continuou até que todas as categorias estivessem saturadas, ou seja, não nenhum dado novo tinha surgido e as categorias estavam bem desenvolvidas em termos de propriedades e dimensões (STRAUSS; CORBIN, 2008). 
- Fase 7 - Codificação axial: relacionou as categorias entre si, associando-as ao nível de propriedades e dimensões (STRAUSS; CORBIN, 2008).

- Fase 8 - Codificação seletiva: integrou e refinou a teoria em torno de um conceito explanatório (STRAUSS; CORBIN, 2008).

- Fase 9 - Elaboração do relatório: acompanhou todas suas fases da pesquisa (STRAUSS; CORBIN, 2008). Em uma GT o texto final exige a "prestação de contas" não somente do produto, mas sobretudo do processo de pesquisa.

- Fase 10 - Avaliação da pesquisa: envolveu a avaliação dos preceitos e procedimentos do método usados para gerar seus resultados (STRAUSS; CORBIN, 2008). O processo de descoberta foi validado com base em seis critérios propostos por Bandeira-de-Mello (2006), ou seja, quanto ao grau de coerência (fit), quanto à funcionalidade, quanto à flexibilidade, quanto à relevância, quanto à densidade e quanto à integração das categorias.

As dez fases do Desenho de Pesquisa foram articuladas em duas etapas e seis passos analíticos que se repetiram em cada uma das etapas, conforme será detalhado na seção 6. A Figura 1, a seguir, ilustra as fases do processo de pesquisa: 


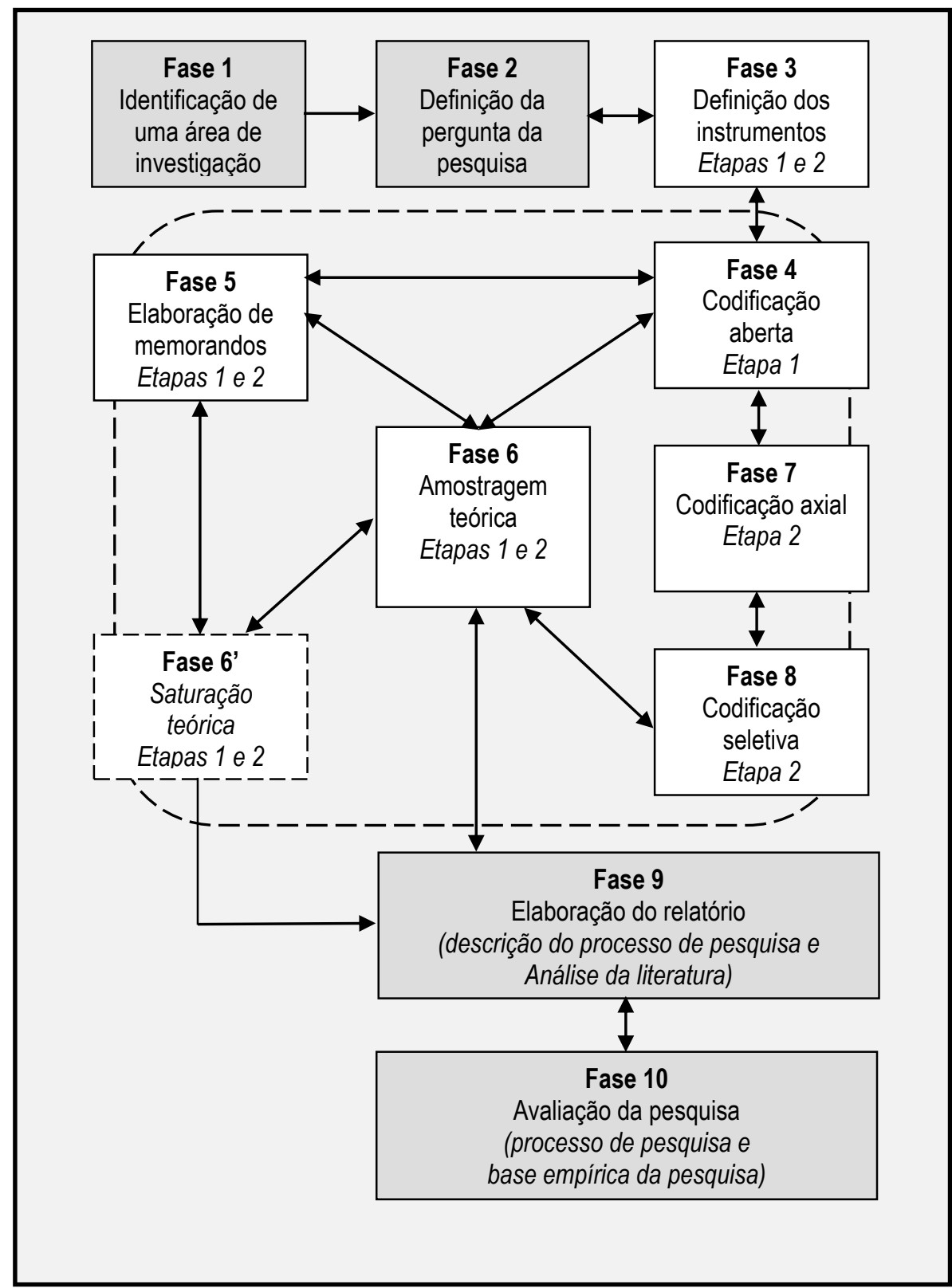

Figura 1: Fases do processo de pesquisa

Fonte: Autores

\section{Participantes, processo explorado e instrumentos de coleta de dados}

O estudo contou a participação de todos os gestores que atuaram na segunda edição do Projeto Aluno Integrado, no âmbito de uma universidade federal. O Projeto foi desenvolvido de julho de 2013 a abril de 2014. Ele compunha o Programa Nacional de Formação Continuada em Tecnologia Educacional, que foi criado pela Portaria $\mathrm{n}^{\circ}$ 522/MEC, de 9 de abril de 1997. A formação foi oferecida para alunos a partir do nono ano do ensino fundamental, com carga horária de 180 horas e duração de cinco meses. O Projeto teve enfoque interdisciplinar, sendo que os temas foram abordados a partir das relações entre informática e a educação básica, contemplando tópicos como conceitos 
básicos de computação, comunicação e produção de conhecimento via web, projetos educacionais e redes de computadores.

Os entrevistados, inicialmente quatro, foram intencionalmente escolhidos, em função do seu papel no Projeto. Todos assinaram o Termo de Consentimento Livre e Esclarecido (TCLE). Foram ouvidos indivíduos que desempenhassem papéis voltados para a tomada de decisão, seja técnica ou administrativa no nível estratégico do Projeto e que tivessem acesso ao LMS, a partir de um Roteiro Inicial das Entrevistas da Etapa 1. A Figura 2 apresenta as funções dos gestores do Projeto:

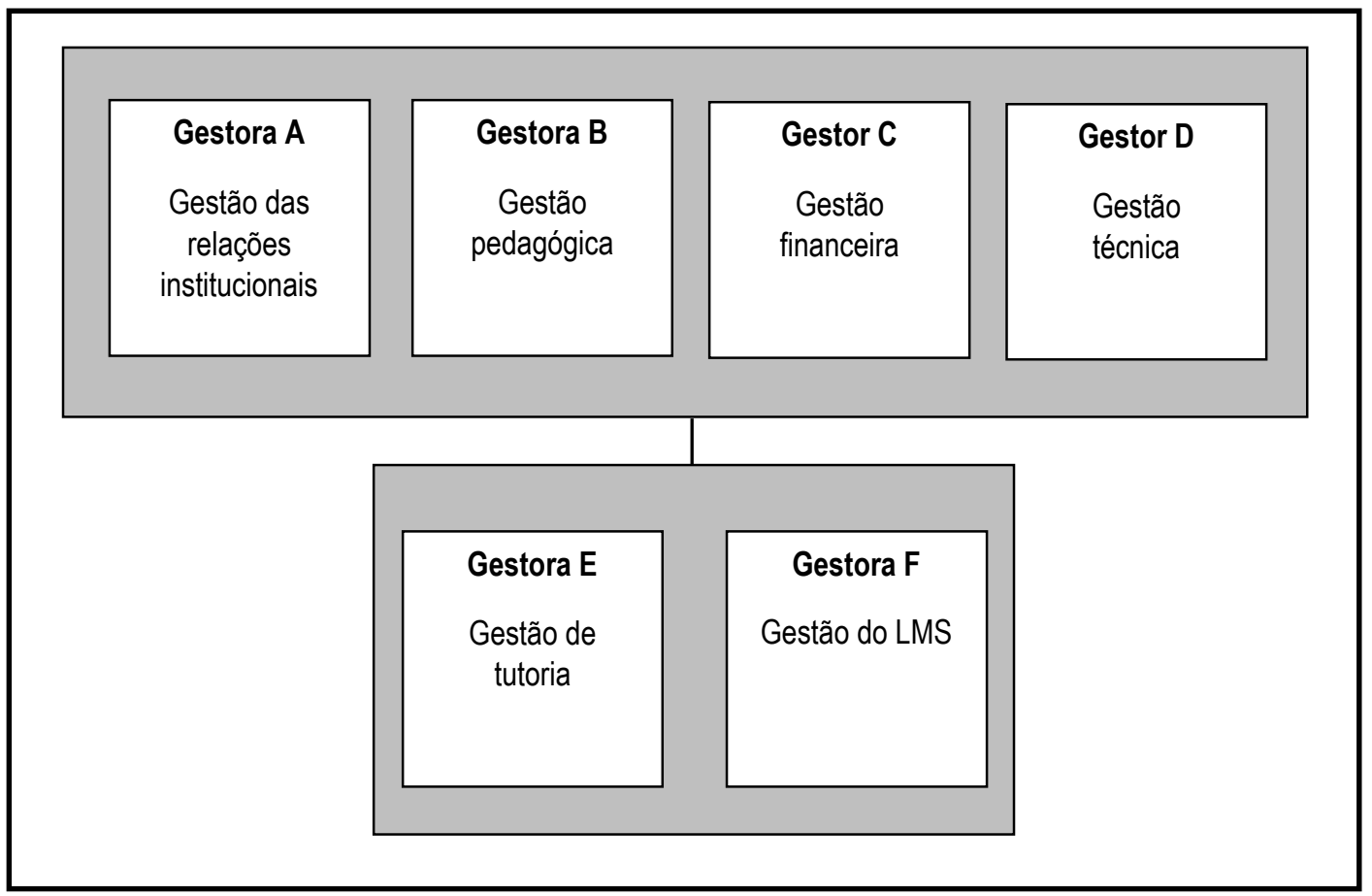

Figura 2: Funções dos gestores do Projeto

Fonte: Autores

Em função da natureza dinâmica do método, que direciona as coletas a partir dos dados de campo, esse escopo foi ampliado na medida em que novos dados foram coletados para que se pudesse caminhar rumo à saturação teórica. Por isso, ao final, seis gestores participaram do estudo. Foi realizada uma segunda entrevista com cada um dos participantes, a partir de um Roteiro Inicial das Entrevistas da Etapa 2. Em ambas as etapas as impressões dos pesquisadores sobre cada entrevista e os passos da análise foram registrados em memorandos. Ao final de cada coleta e após transcrição de cada entrevista, estas foram checadas pelos gestores, a partir do Termo de Validação das Entrevistas.

O processo explorado visou responder ao seguinte problema de pesquisa: "quais são e como atuam os fatores que influenciam a utilização do LMS na gestão da EaD em 
uma universidade pública?". Na pesquisa, os instrumentos para coleta de dados utilizados foram a entrevista e análise de documentos, a partir de orientações de Tarozzi (2011). Eles foram utilizados nas Fases 4, 6 e 8, em cada coleta (conforme o Desenho da Pesquisa), sendo que os instrumentos permitiram uma visão holística do problema (CRESWELL, 2014).

\section{Operacionalizando o pré-campo de pesquisa}

A partir dessa seção assumiremos a utilização da terceira pessoa do plural, para explicitar, de forma mais próxima ao leitor, nossa vivência enquanto pesquisadores, sobre a operacionalização de um GT em SI. Essa prática de redação é comum em estudos que utilizam o método, conforme pode ser observado, por exemplo, em Freitas (2009) e Schröeder (2009) e busca demonstrar a identidade do pesquisador, revelando as razões de suas escolhas durante as análises, aumentando a validade, a confiabilidade da pesquisa e, principalmente sua responsabilidade frente aos dados.

Os procedimentos que antecederam nossa entrada no campo de pesquisa estavam relacionados à preparação no que diz respeito à aproximação com o contexto de pesquisa e à produção de estudos de entorno, sobre técnicas de coleta de dados em pesquisas qualitativas, EaD e GT. Eles proporcionaram nossa aproximação com o tema de pesquisa e com o método. Foram realizadas duas revisões integrativas sobre a produção científica a respeito dos LMS, uma no âmbito internacional e outra no âmbito nacional, que proporcionaram um melhor entendimento e delineamento da pesquisa. Assim como indicado por Bandeira-de-Mello e Cunha (2003), não assumimos um referencial teórico a priori, pois não conhecíamos o que era relevante para os sujeitos envolvidos. Dessa forma, conduzimos a primeira revisão da literatura buscando apresentar um breve estado da arte sobre os principais conceitos envolvidos, com vistas a perceber lacunas (gaps), que poderiam ser preenchidas pela construção da teoria substantiva. Além disso, como indicado por Pinto e Santos (2012), as questões de pesquisa estavam abertas e, evidentemente, não formalizadas na forma de hipóteses específicas.

Além da produção de pesquisas exploratórias, na etapa que antecedeu o campo fizemos contato com a equipe do Projeto Aluno Integrado, para a investigação fosse autorizada. Após sua formalização junto aos gestores, efetuamos a leitura de material e documentos do curso, cedidos pela coordenação, além de consultar o website do curso para compreender seu funcionamento e dinâmica. O problema de pesquisa também 
passou por alterações, pois inicialmente, pretendíamos explorar "o papel do LMS na gestão da EaD”, mas na medida em que o estudo foi sendo desenvolvido, a preponderância em definir os fatores que influenciam a utilização do LMS se consolidou como a questão de pesquisa.

Em seguida, elaboramos o TCLE e o Roteiro Inicial das Entrevistas da Etapa 1, a partir de Strauss e Corbin (2008) e Tarozzi (2011). Esse roteiro foi discutido pelo grupo de pesquisa em reuniões periódicas realizadas durante o segundo semestre de 2013. Para Bandeira-de-Mello e Cunha (2003), é importante que um grupo de pesquisadores possam analisar e questionar continuamente as interpretações para evitar vieses e atenuar as barreiras à sensibilização teórica, o que se buscou colocar em prática neste estudo. No roteiro havia perguntas sensíveis, de natureza prática e estrutural e orientadoras (STRAUSS; CORBIN, 2008). Em seguida, após aproximadamente quinze meses de preparação para o campo, o primeiro entrevistado foi definido, para que, em seguida, e conforme fosse o andamento da coleta de dados, a amostra pudesse ser ampliada. O contato com todos os gestores foi formalizado por e-mail, para confirmação de horário e local das entrevistas.

\section{Operacionalizando o campo e o pós-campo de pesquisa}

Nesta seção são trazidos subsídios, extraídos predominantemente dos memorandos e notas de campo, que desenvolvemos durante o estudo. Além disso, buscamos estabelecer um diálogo com os artigos de Bandeira-de-Mello e Cunha (2003) e de Pinto e Santos (2012), que tiveram como objetivo, respectivamente, desmistificar conceitos inerentes aos processos de análise e codificação do método da GT e contribuir para a discussão da abordagem da GT enquanto estilo de fazer pesquisa. Assim como pontuado por Pinto e Santos (2012), iniciamos o trabalho de campo em um período anterior à coleta de dados formal da pesquisa. Pois ocorreram conversas informais com alguns dos gestores do Projeto, quando buscamos identificar alguns traços básicos do seu cotidiano e iniciar a compreensão da relação entre eles com o curso e o LMS. Esta fase da pesquisa, que ocorreu de forma não sistemática e exploratória, ocorreu entre março e setembro de 2013 e contou com o apoio de anotações sobre aspectos considerados relevantes naquele momento (e que foram considerados para a elaboração do roteiro inicial das entrevistas). 
Como apontam Strauss e Corbin (2008), a teoria formulada deve: apresentar coerência entre dados e resultados, compreensão pelos envolvidos e incorporar generalização suficiente para que variações do fenômeno sejam consideradas e controle na previsão das ações dos envolvidos. Ao invés de tentar chegar a uma versão "real" dos fatos, o pesquisador deve buscar, a todo o momento, apontar as oscilações e as contradições, que constantemente fazem parte dos diversos fragmentos narrativos da pesquisa. A intenção é que ao percorrer os meandros dos discursos e do conjunto dos discursos e da vivência que eles se referem, perseguindo os detalhes, as diferenças, as incoerências, as ambiguidades, o pesquisador possa construir uma interpretação para ampliar o entendimento sobre o contexto da pesquisa (PINTO; SANTOS, 2012). O processo de coleta e análise de dados deve continuar até que os "ganhos marginais", no poder explicativo da teoria, para mais evidências coletadas, seja próximo de nulo (BANDEIRA-DE-MELLO; CUNHA, 2003).

Respeitando essas questões, na pesquisa, os procedimentos de campo envolveram dez fases (de acordo com o Desenho da Pesquisa), duas etapas (de entrevistas com gestores) e os seis passos analíticos, que se repetiram em cada uma das etapas. O Quadro 1 sumariza as atividades dos passos analíticos da pesquisa:

\begin{tabular}{|c|l|}
\hline Passo & \multicolumn{1}{c|}{ Atividade } \\
\hline 1 & realização de entrevista com o gestor e elaboração de memorando \\
\hline 2 & transcrição da entrevista \\
\hline 3 & validação, pelo gestor, da transcrição da entrevista \\
\hline 4 & $\begin{array}{l}\text { análise da entrevista (codificação inicial ou aberta, axial ou seletiva) e elaboração de } \\
\text { memorando }\end{array}$ \\
\hline 5 & a partir da análise, adaptação do roteiro para a próxima entrevista \\
\hline 6 & $\begin{array}{l}\text { realização da entrevista com o próximo gestor (buscando amostragem teórica e a } \\
\text { saturação teórica, em função das análises já realizadas) }\end{array}$ \\
\hline
\end{tabular}

Quadro 1: Passos analíticos

Fonte: Autores

Para Bandeira-de-Mello e Cunha (2003) a saturação teórica deve ser entendida como uma "utopia estimulante", pois seria uma meta que o pesquisador deve perseguir. A busca pela saturação teórica é o limite dos esforços do cientista e dos dados disponíveis, quando nenhum dado novo gera descobertas ou está associado a novas categorias. Durante a operacionalização do processo de codificação (Passo 4) ficou claro que, apesar dos passos analíticos serem apresentados de forma sequencial, eles se sobrepõem, admitindo circularidade. Assim como apontado por Bandeira-de-Mello e Cunha (2003, p. 8) a codificação deve ser mais bem compreendida como "tarefa do pesquisador e não 
como etapa de um processo linear", pois apesar da literatura apontar para um conjunto sistemático de procedimentos, a criatividade é indispensável para a análise dos dados.

A primeira etapa do estudo, composta por seis entrevistas semiestruturadas, teve como objetivo explorar a descrição do contexto, desenvolver categorias, propriedades, dimensões e as proposições da teoria. Inicialmente estavam previstas quatro entrevistas que comporiam o corpus de dados da pesquisa. Entretanto, considerando a sensibilidade do pesquisador (STRAUSS; CORBIN, 2008) e ao buscar compreender detalhes das categorias, propriedades e dimensões ampliamos a amostra (amostragem teórica). Ela envolveu a realização das entrevistas e análise de documentos e consideramos que foram cruciais o exercício e o desenvolvimento da sensibilidade teórica. Para Strauss e Corbin (2008), a sensibilidade teórica refere-se à habilidade de dar significado aos dados, à capacidade de entender e à capacidade para separar o que é pertinente e o que não é pertinente para a pesquisa. Ela é desenvolvida pelo conhecimento científico acumulado pelo pesquisador, pela sua experiência profissional e pessoal. No entanto, a utilização de técnicas e procedimentos é importante para atenuar os preconceitos do cientista no processo interpretativo. Assim, duas tarefas são fundamentais para que o pesquisador possa realizar as análises: elaborar questionamentos sobre os possíveis significados e fazer comparações. Cabe destacar que, na medida em que o trabalho de campo avançava, a análise de dados também ganhava fôlego e o roteiro das entrevistas, gradativamente, sofria alterações em busca da saturação teórica. Assim, convergindo com Pinto e Santos (2012), novas questões eram incluídas, advindas das categorias que emergiam das análises das entrevistas anteriores.

Ao final da primeira etapa de entrevistas, elaboramos um esquema buscando comparar e mapear as questões feitas a cada um dos gestores, para que pudéssemos compreender os caminhos e rumos que cada uma delas tomou. Neste sentido observamos que a entrevista A teve em torno de 25 questões. A entrevista B teve em torno de 24 questões. As entrevistas C e D foram as mais extensas em número de questões (chegando a 27 e 26 intervenções, distintas, respectivamente). Já as entrevistas E e F tiveram, ambas 24 questões, embora distintas. Conforme apontado por Pinto e Santos (2012), percebemos a importância em não manter os instrumentos de coleta de dados fechados, ao contrário, os roteiros das entrevistas foram sendo "talhados" ao longo do processo de pesquisa, sofrendo alterações substanciais em função dos dados que foram sendo revelados pelos gestores. 
Neste momento havia pelo menos 1503 códigos, com média de 250 códigos por entrevista, alguns esboços da teoria, ou seja, categorias iniciais, rascunhos de proposições e muitas indagações sobre os dados. Além disso, também realizamos uma comparação incidente-incidente de forma manual (nas transcrições das entrevistas), buscando comparar as possíveis categorias em suas propriedades e dimensões e avaliando se algum dado novo ou citação teria as mesmas propriedades das demais categorias identificadas.

Percebemos que a dimensionalização das propriedades de uma categoria, que agrega maior valor explicativo da teoria, é um processo fundamental e difícil de operacionalizar, exigindo muita análise e tempo de reflexão para sua construção. Tínhamos a percepção que a fundamentação empírica ganhava força na medida em que os novos dados eram associados às categorias já existentes. O processo de transcrição das entrevistas, apesar de bastante oneroso em termos de tempo, também era um momento muito rico para reflexão sobre os dados e preparação para as interlocuções subsequentes. As transcrições foram checadas e analisadas diversas vezes e levadas para apreciação do grupo de pesquisa.

Devido à grande carga de trabalho, em função da realização de tarefas mecânicas associadas ao gerenciamento de fragmentos de textos e elementos construídos ao longo do processo de análise, recorremos a um software do tipo "programa de apoio à análise qualitativa" (BANDEIRA-DE-MELLO, 2006). Segundo Bandeira-de-Mello e Cunha (2003) é "extremamente recomendável a utilização de um software para apoio às interpretações e organização documental”. O ATLAS.ti é uma alternativa viável, pois foi elaborado principalmente para essa finalidade, seja a construção de teorias. Dessa forma, a partir de março de 2014, passamos a utilizar o software ATLAS.ti versão 7.5.6.

Inicialmente recodificamos a primeira entrevista no software. Neste momento da pesquisa tínhamos muitas dúvidas sobre como fazer com que os dados tivessem sentido. Na primeira análise o objetivo foi partir os dados, trabalhar com as menores unidades de significado possível. A ênfase dos códigos foi em "acompanhamento contínuo", "podendo interferir" e "necessitando de relatórios". Na verdade, na primeira entrevista eram apenas códigos que passamos a agrupar por similaridade, mais tarde, esses códigos foram agrupados em famílias (denominação utilizada pelo software) e reorganizados em função dessas famílias. Foi muito interessante observar o ATLAS.ti auxiliando na "comparação constante" (STRAUSS; CORBIN, 2008), pois chegamos a 148 códigos e 16 famílias, sendo que na primeira análise manual foram 252 códigos na mesma entrevista. Então nos 
perguntamos "como faríamos conferência e correlação entre os códigos tão eficiente sem o software?".

Durante esse período intensificamos pesquisas de como trabalhar corretamente no ATLAS.ti, ou seja, como fazer para que a codificação no software tivesse sentido? Em seguida, codificamos a segunda entrevista no ATLAS.ti. Aos códigos inicialmente elaborados somaram-se novos códigos e principalmente novas dúvidas. O esquema conceitual e de relações começou a ser aprimorado. Neste momento achamos prudente pausar a codificação para realizar novas leituras e reflexões. A mecânica de codificação no software dava a impressão que reduzia nossa capacidade de compreensão do processo. Decidimos consultar novamente teses e dissertações que utilizaram o método, que não se revelaram muito esclarecedoras às inquietações operacionais. Algumas eram demasiadamente mecanicistas, outras simplesmente ignoravam ou simplificavam como chegaram, de fato, aos resultados.

O texto de Suddaby (2006) se mostrou elucidativo, pois a esta altura da pesquisa sentíamos que precisávamos definir claramente "qual caminho analítico iríamos seguir", isso precisava ser feito para esclarecermos como a teoria iria se desenhar. Sentíamos que isso precisava acontecer. A partir da análise dos textos, percebemos que o mais importante era inspiração para a compreensão do processo e não propriamente uma codificação mecanizada no ATLAS.ti. Então retomamos a modelagem do esquema relacional (codificação axial) que se configurou de forma mais clara em meio às reflexões e inspiração, como imaginávamos... Na verdade passamos algumas semanas pensando que precisávamos modelar algo no "papel”, pois desejávamos "liberdade para criar". Não sabíamos como, mas entendíamos nos víamos levados a representar de alguma forma o que estávamos percebendo a partir da análise. Todos os dados estavam simultaneamente circulando por nossos pensamentos o tempo todo.

Até aquele momento da pesquisa, imaginávamos que faríamos mais duas coletas, uma para validar as relações e outra para validar a categoria central e que a categoria central iria emergir após a segunda coleta, algo extremamente linear para um método tão dinâmico. Ledo engano. Algumas semanas se passaram e uma nova versão do esquema teórico foi esboçada, a partir da codificação no software das duas primeiras entrevistas. Observávamos os dados no ATLAS.ti e o esquema anterior... "essas relações faziam sentido?". Nos sentimos confiantes para criar o esquema buscando relacionar as categorias que havíamos encontrado até aquele momento. Foram algumas semanas refletindo sobre o esquema até encerrarmos uma primeira versão, então o desafio seguinte 
era relacionar o esquema teórico e abstrato feito em "papel" com as categorias e os dados no software, sendo que algumas alterações na nomenclatura das categorias precisariam ser feitas. Nosso problema era ver como essas categorias iriam se comportar a partir das próximas entrevistas. Entretanto, antes de iniciar a terceira codificação no ATLAS.ti buscamos explorar ainda mais os dados já codificados. Sabíamos que eram muitos dados e que precisávamos estar atentos às nuances dos mesmos.

Durante algum tempo não tivemos certeza, mas continuamos investigando... A cada dia o esquema era revisto e muitas vezes levemente alterado (nomenclatura das categorias). Em determinado momento, também incluímos a categoria relatórios ou produtos de informação, por perceber que os havíamos ignorado, embora no software ela fosse bem presente. Voltamos à teoria de Strauss e Corbin (2008), que consideramos adequada para nortear as novas decisões. A grande dúvida era "pensamos em determinada condução da pesquisa, o método é flexível, mas a teoria nos apoia?". Novamente recorremos ao artigo de Bandeira-de-Mello e Cunha (2003) e às teses para verificar se nossas decisões faziam sentido quando confrontadas com estudos anteriores. Mais algumas semanas de reflexão e uma pré-categoria central e suas relações foram esboçadas. Fazia sentido tratar o processo de mediação como elemento central, mas precisávamos investigar mais. De qualquer forma, essa expressão inundou nossas mentes de possibilidades e inquietações... "seria esse o processo central?".

Também tínhamos muitas dúvidas em relação às propriedades e dimensões. Ao analisar outras pesquisas, especialmente Freitas (2009), decidimos na medida do possível, privilegiar categorias e não subcategorias, esse recorte iria nos ajudar a manter focados nos elementos principais. Embora ainda tivéssemos dúvidas de como as dimensões das propriedades se manifestariam ou até mesmo se as propriedades podem poderiam ser vistas mesmo como manifestações ou dimensões das categorias. Retornamos para o ATLAS.ti e procuramos confrontar todas as categorias já codificadas com o esquema que estávamos pensando em ser o representativo do processo. Ainda organizamos as famílias e as nomenclaturas das categorias e padrões que nos ajudariam a organizar os dados. Esse trabalho operacional era muito oneroso em relação ao tempo, por isso sempre que resolvíamos mudar algo, precisávamos pensar em como fazer sem perder dados ou interpretá-los de forma incorreta. Pensávamos: "ao manter nossas atividades voltadas para a operacionalização de um software chegaríamos mais perto dos dados?"”

No início da codificação no software percebemos que estávamos muito focados em números de códigos, números por famílias, média de citações por entrevista... os 
números seriam tão importantes assim? Então antes de avançar para codificar as demais entrevistas, decidimos o seguinte: iríamos avançar nas descrições que compreendiam em um dos objetivos específicos da pesquisa, pois acreditávamos que ao escrever sobre a visão dos gestores, as relações e categorias que estávamos propondo, poderiam ser confrontadas com a realidade de uma nova forma, ou seja, "olhar os dados de diferentes perspectivas". Isso nos ajudaria a enxergar melhor o que estava acontecendo, achamos que ficaríamos mais abertos às possíveis variações e novos dados se mergulhássemos, de fato, no contexto. Acreditávamos que essa imersão nos processos dos gestores nos ajudaria a amadurecer o esquema proposto e as relações que foram inicialmente mapeadas, assim como ajudar na codificação de novas entrevistas e relatórios que foram retomados após essa etapa, convergindo com Strauss e Corbin (2008), quando falam da importância da descrição como base para a teorização.

Após as análises das entrevistas para compor as caracterizações, definimos que iríamos alterar a ordem nos objetivos específicos. Pensamos em primeiro caracterizar as atividades dos gestores do Aluno Integrado, para depois caracterizar o curso, a partir da visão dos gestores. Faria mais sentido apresentar os gestores e depois aprofundar suas visões sobre o Projeto e sobre o LMS. Ainda não havíamos decidido que faríamos uma costura entre as visões dos gestores nas caraterizações. Por hora, trabalhamos com a visão de cada um em separado. Para cada gestor, abríamos sua entrevista no editor de texto e procurávamos localizar indícios na sua fala que podiam nos ajudar na caracterização, então destacávamos os trechos já utilizados. Na verdade, começamos com a caracterização dos gestores, para depois caracterizar o LMS e, por fim, caracterizar o Projeto. Não tínhamos um roteiro pré-determinado, como um padrão para cada caracterização, mas procurávamos respeitar o olhar de cada um deles, já que cada entrevista acabou tendo uma estrutura distinta.

Buscando concluir as visões dos gestores em cada objetivo específico, procuramos fazer um sumário das suas ideias principais. Também procuramos nos disciplinar para iniciar e finalizar a visão de cada gestor de cada vez e de escrever essa visão geral ao final dessa análise para aproveitar o "calor do momento" e as ideias que mais marcavam cada análise. Ficamos satisfeitos com os resultados, pois as descrições nos fizeram voltar mais maduros para a análise e para o software. Ao término dessa rodada voltamos às entrevistas e verificamos se havia algo que ficou "escondido" e que não foi apresentado nas descrições, esse foi um trabalho bem minucioso, como uma mineração nos dados. Mesmo que tenha sido muito desgastante, acreditamos que estivéssemos encontrando 
preciosidades e consolidado a análise. Ao finalizar visão dos gestores sobre o curso, percebemos que ainda havia pontos que precisávamos amadurecer, pois havia momentos em que as visões se interconectavam... Enfim, tínhamos a necessidade de pensar em como apresentar essas visões de forma clara e explicitar o que realmente os participantes desejavam dizer.

Nossa intenção era reorganizar o texto, primeiro falando da experiência dos gestores, depois do LMS e por fim do Projeto. Pensamos em incluir a caracterização do Aluno Integrado antes do LMS, mas como muitas falas do curso referiam-se ao LMS, ficava mais claro primeiro tratar do sistema, para depois fechar com uma visão mais macro. Na verdade acabamos invertendo, pois iríamos sair de uma visão macro para a visão micro, mas partimos de uma visão micro (atividades dos gestores) para uma visão macro (sobre o Projeto). No intermeio ficaria o LMS. Ao fazer essa reorganização dos itens, voltamos a para cada entrevista procurando o que não tinha sido considerado, pois havíamos marcado no texto, e caso fosse importante iríamos incluir no texto. Após a revisão das caracterizações, quando transformamos as entrevistas (material bruto) em um texto com início meio e fim, percebemos que precisávamos rever o esquema teórico, complementando as categorias que já haviam sido estabelecidas, a partir das novas considerações.

O mergulho nos dados nos fez perceber elementos importantes que iríamos procurar incorporar no esquema teórico. Nosso desafio era vislumbrar um formato que contemplasse essas caracterizações e respeitasse a codificação que já havíamos iniciado. A partir daí nos sentimos seguros para avançar no sentido de estabelecer as categorias, suas propriedades e dimensões e defini-las a partir das leituras e da codificação já realizada. Essa tarefa também foi muito exaustiva, pois a definição da variação dimensional, em especial, parecia estar oculta no tex to e essa atividade poderia consolidar a saturação teórica. O primeiro passo foi desenhar como seriam essas relações, suas propriedades e dimensões. Buscamos argumentar como poderíamos justificar cada uma das propriedades e suas variações, para isso precisávamos recorrer novamente aos dados, que nos dariam comprovação e robustez empírica. Neste ponto, Freitas (2009) foi bastante esclarecedor em relação ao desenho das categorias. Talvez essa tenha sido uma das fases mais exaustivas, ou seja, percorrer novamente cada uma das entrevistas, buscando subsídios que comprovassem as variações dimensionais. Então, cada entrevista foi novamente analisada quando buscávamos confirmar tanto as categorias quanto as dimensões. Considerando que havia 17 propriedades e seis entrevistas, foram realizadas 
107 buscas nos dados para comprovação. Com esta atividade e após mais de doze meses de análise, finalizamos a primeira etapa do estudo, desenvolvemos a caracterização do Projeto e a definição e consolidação do esquema teórico. Esse esquema foi alicerçado partir dos exercícios de interpretação conduzidos ao longo de todo o processo de análise dos dados, sendo que ao final desta etapa conseguimos expressar uma hipótese fundamental para a teoria.

Após 27 meses do início da pesquisa, inauguramos a segunda etapa do estudo, que teve como objetivo a realização de mais uma entrevista com cada um dos gestores consultados na primeira etapa, a partir do Roteiro Inicial das Entrevistas da Etapa 2 e análises de novos documentos, como relatórios parciais de andamento do Projeto. No roteiro das entrevistas havia perguntas teóricas (que buscavam relacionar um conceito com outro) e de natureza prática e estrutural (STRAUSS; CORBIN, 2008). Nesta etapa, que teve como foco estimular o desdobramento das codificações axial e seletiva, pudemos fazer a validação de categorias, propriedades e dimensões e avançar no processo de análise, validando, empiricamente, a hipótese fundamental e as proposições elencadas pelo estudo. Consolidamos a percepção de que havíamos atingido a saturação teórica e a amostragem teórica, pois consideramos que as categorias estavam adequadamente desenvolvidas. As entrevistas com as gestoras E e F ocorreram em novembro de 2014. Já as entrevistas com os gestores A, B, C e D ocorreram até março de 2015. Nesta etapa, todas as entrevistas também tiveram duração aproximada de uma hora e não ocorreram na mesma ordem da primeira etapa por questões de agenda dos entrevistados. Consideramos que esta coleta de dados foi mais objetiva que a anterior, pelo menos nos sentíamos mais seguros em questioná-los sobre as relações e comportamentos das categorias. Procuramos organizar parte das relações complexas entre as condições e sua relação subsequente com as ações e interações, conforme indicado por Pinto e Santos (2012).

Para que o entendimento fosse facilitado, na entrevista, cada questão era apresentada de forma explícita (por escrito, em papel), assim os gestores apontavam com mais facilidade o que consideravam mais relevante ou menos relevante e como enxergavam as relações. Essa forma de interação ocorreu, pois na primeira entrevista dessa etapa verificamos que as questões estavam um tanto complexas e que seria interessante compor um material de apoio para a condução das mesmas. Os entrevistados não classificavam as relações como causais, intervenientes ou contextuais, mas buscavam validar as relações identificando os mecanismos de ações ou interações em cada um deles. 
A ideia dessa coleta era encontrar indícios que pudessem tanto validar ou não as relações, quanto comprová-las empiricamente e avaliar a saturação teórica das categorias, assim como também discutir a categoria central da teoria.

Após os procedimentos de campo da pesquisa, os procedimentos pós-campo envolveram a investigação das ações/interações da categoria central, a partir dos dados já coletados. Naquele momento, buscamos estabelecer e registrar critérios e estratégias para o encontro da teoria proposta na pesquisa, frente ao contexto de estudos já desenvolvidos, conforme orientações de Strauss e Corbin (2008). Ressaltamos ainda a importância dos memorandos, pois foram fundamentais ao longo do processo de pesquisa, pois além nos manterem envolvidos na análise, nos ajudaram a aumentar o nível de abstração minhas ideias e proporcionaram o registro do caminho analítico. Conforme a pesquisa avançava, os registros eram incorporados à pesquisa, para apresentação das categorias e dimensões, por exemplo.

Ao final do processo, conforme apresentado por Bandeira-de-Mello (2006) foi importante discutirmos a avaliação da qualidade de uma GT. Dessa forma, no contexto da pesquisa relatada por este artigo, os critérios são atendidos da seguinte forma:

(1) quanto ao grau de coerência (fit), a pesquisa é aderente a um contexto específico e bem definido;

(2) quanto à funcionalidade, os resultados podem ser verificados pela construção do esquema teórico que organizou a hipótese central da teoria em torno da categoria central e que também foi embasada empiricamente nos dados e validada junto aos participantes do estudo;

(3) quanto à flexibilidade, a pesquisa foi construída de modo que novos casos possam ser incorporados e possam aumentar seu escopo;

(4) quanto à relevância, na investigação validou-se, junto aos participantes, sua visão a respeito dos achados;

(5) quanto à densidade, ao final, foram gerados 23 códigos, 576 citações e 6 notas de análises, ou memorandos, que correspondem a cada uma das categorias, além dos memorandos das entrevistas. Dos 23 códigos gerados, 17 eram de primeira ordem, ou seja, aqueles diretamente ligados às citações, e os outros seis eram construtos teóricos abstratos, que correspondiam às categorias. A relação entre códigos e citações, na ordem de 6/17/576, fornece evidências de que há um grau de densidade teórica, visto que poucos construtos teóricos estão relacionados a um número significativo de outras categorias e citações; 
(6) quanto à integração, na pesquisa todas as categorias foram integradas à categoria central e essa integração foi embasada empiricamente nos dados com o apoio do software ATLAS.ti.

A partir da experiência de construção da teoria, percebemos, com clareza, a circularidade ou não linearidade do método, que são necessários para que se tenha entendimento e maturidade em delinear as categorias e suas relações, convergindo com Suddaby (2006). O processo de pesquisa em GT não é "perfeito" no sentido de sequencialidade e de previsibilidade dos achados e das ações do pesquisador. É preciso estar aberto para idas e vindas, avanços e retrocessos e novos avanços, que procuramos ilustrar neste texto. Se pesquisador não atendar aos detalhes e sutilezas dos dados, privilegiando a automação da análise, a pesquisa poderá ter bons indicadores quantitativos no software, mas constituir-se de maneira rasa ou superficial.

Como dizem Strauss e Corbin (2008), o desafio é aliar "objetividade e sensibilidade" na construção da teoria e no entendimento de um processo. Este foi um dos nossos principais desejos, enquanto "instrumentos" de análise, compreensão e organização dos dados. Ressaltamos que nesta seção buscamos apresentar "como" e "em que base" a amostragem original foi apoiada e "como" as principais categorias surgiram. Também buscamos apresentar como foi feita a amostragem teórica e depois que amostragem teórica foi feita, o quanto as categorias se mostraram representativas dos dados e como procuramos chegar à saturação teórica.

\section{Considerações finais e lições aprendidas}

O objetivo deste artigo foi alcançado, pois o percurso metodológico da operacionalização de uma GT foi apresentado. A evolução da Tecnologia da Informação (TI) e seus impactos nos âmbitos social, econômico e educacional tem se mostrado, um campo fértil para a pesquisa (SHAIKH; KARJALUOTO, 2015). Esses impactos, em parte, ainda são desconhecidos e explorados, muitas vezes, de forma incipiente e pouco integrada, diante da complexidade de fatores envolvidos e da variedade de software e hardware, além da sua rápida dinâmica de absorção e substituição por novas tecnologias. Neste sentido, a pesquisa retratada por este artigo validou a seguinte hipótese fundamental: "na gestão da EaD o LMS é orientado essencialmente pelo Processo de Mediação, que pode influenciar (e pode ser influenciado) por Elementos internos, Agentes externos, Intenções do gestor no uso do LMS e pela Compreensão da situação 
pelo gestor. O Processo de Mediação, moderado pela Compreensão da situação, pode influenciar (e ser influenciado) pelas Sensações do gestor no uso do LMS. As Intenções do gestor no uso do LMS, por sua vez, também podem influenciar (e podem ser influenciadas) pelas Sensações do gestor no uso do LMS, pelos Elementos internos e pelos Agentes externos".

O estudo buscou capturar de forma ampla e fundamentada empiricamente nos dados, aspectos até então delineados de forma dispersa e não integrados pela literatura da área, apresentando um paradigma que considera estrutura e processo e organiza conexões entre os dados, revelando fatores e como esses fatores influenciam a utilização do LMS na gestão da $\mathrm{EaD}$ em uma universidade pública, em uma dinâmica que integra elementos educacionais e administrativos. A pesquisa também respondeu às teorias gerais sobre a utilização de LMS na gestão, sob a perspectiva dos gestores de $\mathrm{EaD}$. Os achados da teoria substantiva foram analisados sob a ótica da literatura e se buscou identificar pontos convergentes e divergentes. Percebeu-se que embora grande parte dos resultados, especialmente das proposições, tenha encontrado amparo teórico, nenhum dos estudos apresentou os componentes do paradigma da teoria substantiva revelados, bem como as condições causais, condições intervenientes, ações/interações e consequências revelados. Portanto, a pesquisa desenvolvida à luz da GT representa um avanço no sentido de contribuir com um olhar sistêmico do SI como elemento mediador administrativo/educacional, reconhecendo seus componentes e sua dinâmica.

A condução de uma pesquisa que adota a GT é angustiante e conflituosa em detrimento da sua não linearidade, daí a importância de envolver mais de um pesquisador. Os encontros do grupo de pesquisa socializaram as descobertas e validaram as decisões. Sabemos que ainda temos muito para aprender sobre o método e este artigo é uma iniciativa para que possamos discuti-lo junto à comunidade acadêmica.

Destacamos que a principal lição apreendida compreendeu a constatação de que utilizamos um método analítico cientificamente robusto para a condução de pesquisas qualitativas. Dessa forma, uma Grounded Theory:

- $\quad$ está embasada empiricamente nos dados e os dados não mentem;

- exige notável criatividade e sabedoria dos pesquisadores para encontrar ligações e relações explicitamente ocultas e implicitamente reveladas nos dados;

- deve privilegiar, na revisão inicial de literatura, somente os conceitos elementares do tema de pesquisa, apontando-se as lacunas teóricas; 
- $\quad$ se fortalece pela validação constante nos dados, pois a realidade dos participantes conduz a pesquisa e seus achados;

- tem seu ordenamento lógico intensificado pela busca da saturação teórica;

- precisa definir rigorosamente sua categoria central, para que se possa articular, de fato, as relações e apresentar as etapas do processo explorado e,

- ao trazer, ao final do estudo, o confronto com demais teorias, aponta lacunas preenchidas e estabelece novas oportunidades para enriquecer investigações complementares com abordagens mais tradicionais.

A partir da experiência na operacionalização do percurso metodológico de uma GT, percebemos que o método estimula a ousadia dos pesquisadores. Neste sentido, diante do complexo processo analítico, são requisitos fundamentais no sucesso da pesquisa, a sensibilidade e a empatia. Para gerir o processo de construção de uma GT é preciso buscar o equilíbrio entre o rigor científico, criatividade e inspiração em movimentos antagônicos, dotados de harmonia e conflito, sobre o que sabemos e o que achamos que sabemos. É no exaustivo reconhecimento do contraditório que a teoria é enraizada e sustentada.

\section{Referências}

APRAMIAN, T. et al. (Re)Grounding grounded theory: a close reading of theory in four schools. Qualitative Research, Nova Iorque, v. 17, n. 4, p. 359-376, oct. 2016.

BANDEIRA-DE-MELLO, R. Softwares em pesquisa qualitativa. In: GODOI, C. K; BANDEIRA-DE-MELLO, R.; SILVA, A. B. (Org.). Pesquisa qualitativa em estudos organizacionais: paradigmas, estratégias e métodos. 1. ed. São Paulo: Saraiva, 2006. p. 429460 .

BANDEIRA-DE-MELLO, R.; CUNHA, C. Operacionalizando o método da grounded theory nas pesquisas em estratégia: técnicas e procedimentos de análise com apoio do software ATLAS/TI. In: ENCONTRO DE ESTUDOS EM ESTRATÉGIA, 1,2003, Curitiba. Anais... Curitiba: ANPAD, 2003. p. 1-18.

BIANCHI, E. M. P. G.; IKEDA, A. A. Usos e aplicações da grounded theory em administração. Revista Gestão. Org, São Paulo, v. 6, n. 2, p. 231-248, mai. 2008.

BLUMER, H. Simbolic interacionism. 1. ed. Englewood Cliffs: Prentice Hall, 1969.

CHARMAZ. K. A construção da teoria fundamentada: guia prático para análise qualitativa. 1. ed. Porto Alegre: Artmed, 2009.

CRESWELL, J. W. C. Research design: qualitative, quantitative, and mixed methods approaches. 4. ed. Los Angeles: Sage, 2014. 
DENZIN, N.; LINCOLN, Y. The sage handbook of qualitative research. 3. ed. Los Angeles: Sage, 2005.

FREITAS, A. S. A implementação do e-learning nas escolas de gestão: um modelo integrado para o processo de alinhamento ambiental. 2009. 330 f. Tese (Doutorado em Administração) Pontifícia Universidade Católica do Rio de Janeiro, Rio de Janeiro, 2009.

HOPFER, K. R.; MACIEL-LIMA, S. M. Grounded Theory: avaliação crítica do método nos estudos organizacionais. Revista FAE, Curitiba, v. 11, n. 2, p. 15-24, jul./dez. 2008.

KUHN, T. S. The structure of scientific revolutions. 2. ed. Chicago: University of Chicago Press, 1970.

MORGAN, G. Paradigms, metaphors, and puzzle solving in organization theory. Administrative Science Quarterly, Nova Iorque, v. 25, n. 4, p. 605-622, dec. 1980.

MURPHY, C.; KLOTZ, A. C.; KREINER, G. E. Blue skies and black boxes: The promise (and practice) of grounded theory in human resource management research. Human Resource Management Review, Amsterdã, v. 27, n. 2, p. 291-305, june. 2016.

PINTO, M. R.; SANTOS, L. L. S. A grounded theory como abordagem metodológica: relatos de uma experiência de campo. O\&S, Salvador, v. 19, n.62, p. 417-436, jul./set. 2012.

SCHRÖEDER, C. Educação a distância e mudança organizacional na escola de administração da UFRGS: uma teoria substantiva. 2009. 252 f. Tese (Doutorado em Administração de Empresas) - Escola de Administração, Universidade Federal de Rio Grande do Sul, Porto Alegre, 2009.

SHAIKH, A.; KARJALUOTO, H. Making the most of information technology e systems usage: a literature review, framework and future research agenda. Computers in Human Behavior, Amsterdã, v. 49, p. 541-566, aug. 2015.

STRAUSS, A.; CORBIN, J. Pesquisa qualitativa: técnicas e procedimentos para o desenvolvimento de teoria fundamentada. 2. ed. Porto Alegre: Artmed, 2008.

SUDDABY, R. From the editors: what grounded theory is not. Academy of Management Journal, Nova Iorque, v. 49, n. 4, p. 633-642, aug. 2006.

TAROZZI, M. O que é a grounded theory: metodologia de pesquisa e de teoria fundamentada nos dados. 1. ed. Petrópolis: Vozes, 2011.

TAYLOR, J. S.; BOGDAN, R. Introduction to qualitative research methods: a guidebook and resource. 3. ed. New York: John Wiley \& Sons, 1998.

Recebido em: 28 de maio de 2018.

Aceito em: 04 de dezembro de 2018. 